\title{
Papers
}

\section{Effects of stretching before and after exercising on muscle soreness and risk of injury: systematic review}

\author{
Rob D Herbert, Michael Gabriel
}

\begin{abstract}
Objective To determine the effects of stretching before and after exercising on muscle soreness after exercise, risk of injury, and athletic performance. Method Systematic review.

Data sources Randomised or quasi-randomised studies identified by searching Medline, Embase, CINAHL, SPORTDiscus, and PEDro, and by recursive checking of bibliographies.

Main outcome measures Muscle soreness, incidence of injury, athletic performance.

Results Five studies, all of moderate quality, reported sufficient data on the effects of stretching on muscle soreness to be included in the analysis. Outcomes seemed homogeneous. Stretching produced small and statistically non-significant reductions in muscle soreness. The pooled estimate of reduction in muscle soreness 24 hours after exercising was only $0.9 \mathrm{~mm}$ on a $100 \mathrm{~mm}$ scale $(95 \%$ confidence interval -2.6 $\mathrm{mm}$ to $4.4 \mathrm{~mm}$ ). Data from two studies on army recruits in military training show that muscle stretching before exercising does not produce useful reductions in injury risk (pooled hazard ratio 0.95 , 0.78 to 1.16 ).

Conclusions Stretching before or after exercising does not confer protection from muscle soreness. Stretching before exercising does not seem to confer a practically useful reduction in the risk of injury, but the generality of this finding needs testing. Insufficient research has been done with which to determine the effects of stretching on sporting performance.
\end{abstract}

\section{Introduction}

Many people stretch before or after engaging in athletic activity. Usually the purpose is to reduce muscle soreness after exercising (with delayed onset), to reduce risk of injury, or to improve athletic performance. $^{1-7}$

This review synthesises research findings of the effects of stretching before and after exercising on delayed onset muscle soreness, risk of injury, and athletic performance. We carried out a systematic review to minimise bias. ${ }^{8}$

\begin{abstract}
Methods
The protocol was specified before the review was undertaken.
\end{abstract}

\section{Inclusion and exclusion criteria}

The review included randomised or quasi-randomised studies that investigated the effects of any stretching technique, before or after exercising, on delayed onset muscle soreness, risk of injury, or athletic or sporting performance. Studies were included only if stretching was conducted immediately before or after exercising. Studies reported in languages other than English were not included as translations were not available.

\section{Search strategy}

Relevant studies were identified by searching Medline (1966 to February 2000), Embase (1988 to February 2000), CINAHL (1982 to January 2000), SPORTDiscus (1949 to December 1999) and PEDro (to February 2000). In Medline, a translation of the optimum OVID search strategy of Dickersin et al was combined with specific search terms for each topic shown in the box. ${ }^{9}$ The Medline search strategy was translated into comparable search strategies for Embase, CINAHL, and SPORTDiscus. PEDro was searched with the terms "stretch," "exercise," "warm-up," and "cool-down" in the abstract field. Bibliographies of studies identified by electronic searches were then searched recursively until no more studies were identified. MG screened search results for potentially eligible studies, and uncertainties about the eligibility of a particular study were resolved by discussion with $\mathrm{RDH}$.

\section{Assessment of study quality}

Methodological quality was assessed with the PEDro scale, which is based on the Delphi list. ${ }^{10}$ We used this scale because its items were thought to be important by a panel of experts, ${ }^{10}$ its reliability is supported empirically, ${ }^{11}$ and we have extensive experience in the use of this scale (http://ptwww.cchs.usyd.edu.au/ pedro). A total score out of 10 is derived for each study from the number of criteria that are satisfied (see footnote in table 2 for a brief description of criteria). The quality of included studies was assessed independently by two assessors, and disagreements were resolved by a third independent assessor. Only studies scoring at least 3 were considered in the initial analysis.
Editorial by MacAuley and Best

School of Physiotherapy, University of Sydney, PO Box 170, Lidcombe, New South Wales 1825, Australia Rob D Herbert senior lecturer Michael Gabriel physiotherapist

Correspondence to: R D Herbert R.Herbert@fhs. usyd.edu.au

bmj.com 2002;325:468 


\section{Topic specific search terms used in OVID} search of Medline

(1) stretch $\$ . m p$

(2) flexib\$.mp

(3) (range adj2 motion).mp

(4) (range adj2 joint).mp

(5) (warmup or warm-up or warm up or cooldown or cool-down or cool down).mp

(6) 1 or 2 or 3 or 4 or 5

(7) athletic injuries.sh

(8) (sore $\$$ adj3 musc\$).mp

(9) sports.sh

(10) exercise.sh

(11) exertion.sh

(12) 7 or 8 or 9 or 10 or 11

(13) 6 and 12 and [final search of optimal search strategy] These terms were combined with the optimum search terms described by Dickersin et al. ${ }^{9}$

\section{Data extraction}

All studies investigating effects of stretching on muscle soreness were scored on numerical scales, but the scale metric varied across studies. To facilitate pooling, soreness scores were converted to percentages of the maximum possible score. For ease of interpretation, soreness data are reported as $\mathrm{mm}$ on a $100 \mathrm{~mm}$ analogue scale.

Some studies reported means and standard deviations of scores before and after the test, but not of changes from before to after the test. To calculate standard deviations of change scores, we assumed that the correlation between before and after tests was $0.5 .^{12}$ Crossover studies reported standard deviations in cells but not standard deviations of paired differences, so the standard deviations of the differences were calculated in the same way. The true value of the correlations is likely to be higher than 0.5 , so the variances of estimates derived from these data are likely to be conservative. Raw time to event data from two published studies were obtained directly from the authors.

\section{Data synthesis}

Where more than one study was available on a particular outcome, we assessed homogeneity of subjects, interventions, and outcomes. Results of comparable studies were pooled in meta-analyses. Meta-analysis of continuous outcomes (scores for muscle soreness) was performed with a fixed effects model using the inverse of the estimated sampling variances as weights. ${ }^{12}{ }^{13}$ The time to event data were analysed with Cox regression.

\section{Results}

\section{Search results}

Only one small and inconclusive study investigated effects of stretching on athletic performance, so these are not discussed further in this review. ${ }^{14}$ Six studies investigated effects of stretching on delayed onset muscle soreness, and two investigated effects of stretching on the risk of injury (table 1).

\section{Methodological quality of included studies}

The reliability of quality ratings was acceptable $(\kappa=0.71$, agreement $=87 \%$ ). The methodological quality of the studies was generally moderate (table 2 ). The range of quality scores was 2-7 (mean 4.1) out of 10 . Not all cri- teria on the PEDro scale can be satisfied in these studies (for example, blinding of subjects is difficult or impossible). Often a report did not clearly specify that a criterion was met, and consequently we scored the study as not satisfying the criterion. We expect that in several of these studies the criterion was met. For example, two studies of muscle soreness did not clearly report loss to follow up. These studies had very short follow up periods, so loss to follow up was probably low or zero. Two studies did not provide sufficient data to permit inclusion in the meta-analysis. ${ }^{18}{ }^{20}$

\section{Effect of stretching on delayed onset muscle soreness}

Five studies (Wessel and Wan reported two studies ${ }^{19}$ ) yielded data of effects of stretching on delayed onset muscle soreness. ${ }^{15-17} 19$ The studies were reasonably homogeneous with respect to participants' characteristics and interventions. In all studies, participants were healthy young adults. Total stretch time per session varied from 300 seconds to 600 seconds, with the exception of one study in which total stretch time was only 80 seconds. ${ }^{16}$ Three studies evaluated stretching after exercising, and two evaluated stretching before exercising. ${ }^{15-17}{ }^{19}$ As there was no evidence of heterogeneity in the outcomes of the studies ( $\mathrm{Q}$ test of heterogeneity ${ }^{13}: \mathrm{P}=0.97$ at 24 hours, $\mathrm{P}=0.99$ at 48 hours, and $\mathrm{P}=0.53$ at 72 hours), we combined studies using stretching both before and after exercising in the meta-analysis (fig 1).

Data from 77 subjects were pooled (27 subjects allocated to stretch groups only, 20 subjects allocated to control groups only, and 30 subjects allocated to both stretch and control conditions). Figure 1 shows the findings of individual studies and pooled estimates. The pooled mean effects of stretching on muscle soreness at 24,48 , and 72 hours after exercising were $-0.9 \mathrm{~mm}$ (on a $100 \mathrm{~mm}$ scale, negative values favour stretching; $95 \%$ confidence interval $-4.4 \mathrm{~mm}$ to $2.6 \mathrm{~mm}, \mathrm{P}=0.70$, $\mathrm{n}=77), 0.3 \mathrm{~mm}(-4.0 \mathrm{~mm}$ to $4.5 \mathrm{~mm}, \mathrm{P}=0.45, \mathrm{n}=77)$, and $-1.6 \mathrm{~mm}(-5.9 \mathrm{~mm}$ to $2.6 \mathrm{~mm}, \mathrm{P}=0.77, \mathrm{n}=67)$, respectively. Sensitivity analysis indicated that the choice of

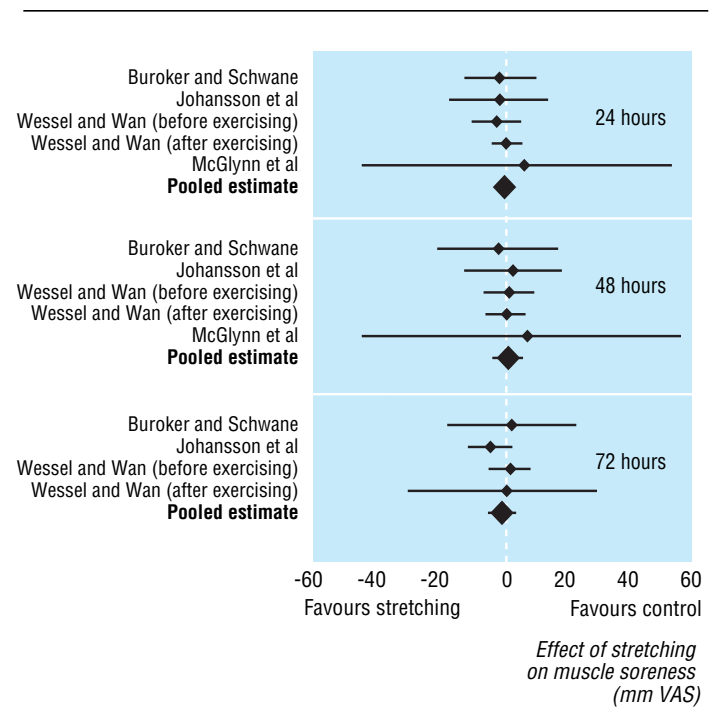

Fig 1 Effects of stretching on delayed onset muscle soreness at 24 hours, 48 hours, and 72 hours after exercise. (VAS=visual analogue scale) ${ }^{15-17} 19$ 
threshold quality score and assumptions about correlations between repeated measures had little effect on this result.

\section{Effect of stretching on risk of injury}

Two studies evaluated the effects of stretching before exercising on the risk of injury in new military recruits undergoing 12 weeks of initial training. ${ }^{21}{ }^{22}$ The first study investigated effects of supervised stretching of calf muscles before exercising (two stretches of soleus and gastrocnemius muscles for 20 seconds on each limb, total stretch time 160 seconds) on risk of six specific leg injuries (lesions of the Achilles tendon, lateral ankle sprains, stress fractures to the foot and tibia, periostitis, or anterior tibial compartment syndrome). The second study investigated effects of supervised stretching of six muscle groups in the lower limbs before exercising (one 20 second stretch to each muscle group on each limb, total stretch time 240 seconds) on risk of soft tissue injury, bone injury, and all injury. Recruits were considered to have sustained an injury if they were unable to return to full duties without signs or symptoms in three days. In both studies, subjects in both stretch and control groups also performed gentle warm up exercises. The two studies yielded similar estimates of risk reduction (hazard ratios 0.92 (0.52 to 1.61 ) and 0.95 (0.77 to 1.18$)$; fig 2 ).

Risks of injury in the two studies differ because injury is defined differently. Time to event data (2630

Table 1 Description of studies included in systematic review

\begin{tabular}{|c|c|c|c|c|}
\hline Study & Design & Subjects & Interventions & Outcome measurement \\
\hline Johansson et al ${ }^{16}$ & Within subjects & $\begin{array}{l}10 \text { healthy female volunteers with } \\
\text { mean (SD) age of } 24(3) \text { years. } \\
\text { Exclusion: taking anti-inflammatory } \\
\text { drugs, experiencing symptoms of } \\
\text { musculoskeletal injury to leg, } \\
\text { participation in weight training }>3 \\
\text { hours/week, experiencing delayed } \\
\text { onset muscle soreness at time of test }\end{array}$ & $\begin{array}{l}\text { Soreness in knee flexor muscles } \\
\text { induced with maximal eccentric } \\
\text { contractions. Before exercise, four } \\
\text { stretches (hurdle position) performed } \\
\text { on experimental leg. Each stretch held } \\
\text { for } 20 \text { seconds }\end{array}$ & $\begin{array}{l}\text { Muscle soreness measured } 0,24,48, \\
\text { and } 96 \text { hours after exercise on } 100 \\
\text { mm visual analogue scale }\end{array}$ \\
\hline High et al ${ }^{18}$ & Between subjects & $\begin{array}{l}62 \text { volunteers ( } 31 \text { women and } 31 \\
\text { men), mean age } 19.5 \text { years. Exclusion: } \\
\text { training in past } 6 \text { months involving } \\
\text { step climbing }\end{array}$ & $\begin{array}{l}\text { Soreness in leg muscles induced with } \\
\text { step test. Before exercise, stretch } \\
\text { group performed two quadriceps } \\
\text { stretches, each of } 50 \text { seconds' } \\
\text { duration }\end{array}$ & $\begin{array}{l}\text { Muscle soreness measured } 24 \text { hours } \\
\text { after the step test on } 0-6 \text { scale }\end{array}$ \\
\hline$\overline{\text { Wessel and Wan }}{ }^{19}$ & Within subjects & $\begin{array}{l}\text { Two samples, each of } 10 \text { subjects. } \\
\text { Experiment } 1 \text { involved two women and } \\
\text { eight men, mean age } 24.2 \text { years. } \\
\text { Experiment } 2 \text { involved five women and } \\
\text { five men, mean age } 25.2 \text { years. } \\
\text { Exclusion: history of back or leg injury } \\
\text { or disease }\end{array}$ & $\begin{array}{l}\text { Soreness in knee flexor muscles was } \\
\text { induced with concentric or eccentric } \\
\text { contractions. Knee flexor muscles of } \\
\text { experimental leg were stretched before } \\
\text { exercise in experiment } 1 \text { and after } \\
\text { exercise in experiment } 2 \text {. Ten stretches } \\
\text { were performed, each of } 60 \text { seconds' } \\
\text { duration }\end{array}$ & $\begin{array}{l}\text { Muscle soreness measured } 12,24,36 \text {, } \\
48,60 \text {, and } 72 \text { hours after exercise on } \\
100 \mathrm{~mm} \text { visual analogue scale }\end{array}$ \\
\hline Pope et $a^{21}$ & Cluster randomised & $\begin{array}{l}1538 \text { male army recruits ( } 39 \\
\text { platoons), aged } 17-35 \text { years. } \\
\text { Exclusion: history of any significant } \\
\text { injury }\end{array}$ & $\begin{array}{l}\text { Each participant performed physical } \\
\text { workout once every second day for } 11 \\
\text { weeks ( } 40 \text { sessions). Before exercise, } \\
\text { experimental group performed } 20 \\
\text { second stretches of gastrocnemius, } \\
\text { soleus, hamstring, quadriceps, hip } \\
\text { adductor, and hip flexor muscle } \\
\text { groups bilaterally }\end{array}$ & $\begin{array}{l}\text { Participants were observed for } \\
\text { duration of } 12 \text { week training } \\
\text { programme. Leg injuries were } \\
\text { recorded if they prevented the subject } \\
\text { from returning to activity within } 3 \\
\text { days, free of signs and symptoms }\end{array}$ \\
\hline Pope et al ${ }^{22}$ & Cluster randomised & $\begin{array}{l}1093 \text { male army recruits }(26 \\
\text { platoons), aged } 17-35 \text { years. } \\
\text { Exclusion: significant pre-existing } \\
\text { injury }\end{array}$ & $\begin{array}{l}\text { Each participant performed physical } \\
\text { workout once every second day for } 11 \\
\text { weeks ( } 40 \text { sessions). Before } \\
\text { exercising, experimental group } \\
\text { performed two } 20 \text { second stretches of } \\
\text { the soleus and gastrocnemius muscle } \\
\text { groups bilaterally. Control group } \\
\text { stretched arm muscles instead }\end{array}$ & $\begin{array}{l}\text { Participants were observed for } \\
\text { duration of } 12 \text { week training } \\
\text { programme. Ankle sprains, stress } \\
\text { fractures of the tibia or foot, } \\
\text { periostitis, Achilles tendonitis, and } \\
\text { anterior compartment syndrome were } \\
\text { recorded if they prevented subject } \\
\text { from returning to activity within } 3 \\
\text { days, free of signs and symptoms }\end{array}$ \\
\hline
\end{tabular}






Fig 2 Survival curves from studies of Pope at al 1998 and Pope et al 2000, showing risk of injury in army recruits undergoing training 2122

subjects, 65 platoons) were combined; 1284 subjects (32 platoons) were allocated to stretch groups and 1346 (33 platoons) to control groups. The discrepancy in sample size occurred because subjects were quasi randomly allocated to an odd number of platoons by military personnel who did not participate in the studies, and then platoons were randomly allocated to groups by the experimenters. A total of 181 injuries occurred in stretch groups and 200 injuries in control groups. Survival curves for stretch and control groups were similar (fig 2). For the meta-analysis the data were analysed with a Cox regression model that incorporated a study factor (study $1^{22}$ or $2^{21}$ ) and a stretch factor (stretch or control). An interaction term was also included in the model initially but was subsequently omitted because it did not contribute significantly
$(\mathrm{P}=0.88)$. Additional analyses were undertaken to take account of possible clustering of outcomes by platoon, but the results were essentially identical so are not reported here. ${ }^{23}$ The pooled estimate of the hazard ratio for the stretch factor was 0.95 ( 0.78 to $1.16, \mathrm{P}=0.61$ ).

\section{Discussion}

This systematic review finds clear evidence from five studies of nominally moderate quality that stretching before or after exercising has no effect on delayed onset muscle soreness. Two further studies on army recruits undergoing military training strongly suggest that muscle stretching before exercising does not produce meaningful reductions in the risk of injury. Not enough research has been done to draw conclusions about the effects of stretching on athletic performance.

\section{Eliminating potential bias}

These conclusions are consistent with at least one review of the effects of stretching, but not others. ${ }^{24-26}$ Unlike earlier reviews, we used a systematic review methodology to eliminate potential sources of bias as far as possible, but this does not guarantee the absence of bias. Our review may have been biased by publication bias or by inclusion only of studies reported in English. ${ }^{27}{ }^{28}$ Both factors would be expected to inflate estimates of the effects of treatments, yet we found that stretching has no effect on delayed onset muscle soreness or on risk of injury. When we performed a less sensitive search for studies in languages other than English we found no studies that satisfied the inclusion criteria. The PEDro scale, which we used to discriminate between studies of different quality, has not been fully validated. Use of the PEDro scale is, however, unlikely to have biased our conclusions as study findings were consistent (fig 1). Meta-analysis of almost any combination of the included studies is likely to have produced similar findings.

\section{Effect of stretching on delayed onset muscle soreness}

The results of five studies (77 subjects) imply that stretching reduces soreness in the 72 hours after exer-

Table 2 Quality scores of studies in systematic review

\begin{tabular}{|c|c|c|c|c|c|c|c|c|c|c|c|c|c|}
\hline \multirow[b]{2}{*}{ Study } & \multicolumn{13}{|c|}{ Scores on PEDro scale* } \\
\hline & Outcome & 1 & 2 & 3 & 4 & 5 & 6 & 7 & 8 & 9 & 10 & 11 & Total score \\
\hline Buroker and Schwane ${ }^{15}$ & Soreness & - & + & $?$ & $?$ & - & - & - & + & $?$ & + & + & $4 / 10$ \\
\hline Johansson et $\mathrm{a}^{16}$ & Soreness & + & + & $?$ & + & - & - & - & + & $?$ & + & + & $5 / 10$ \\
\hline McGlynn et $\mathrm{al}^{17}$ & Soreness & - & + & $?$ & + & - & - & - & + & $?$ & + & + & $5 / 10$ \\
\hline High et al ${ }^{18}$ & Soreness & - & + & $?$ & $?$ & - & - & - & + & $?$ & + & - & $3 / 10$ \\
\hline Wessel and Wan $^{19}$ & Soreness & - & + & $?$ & + & - & - & - & $?$ & $?$ & + & + & $4 / 10$ \\
\hline${\text { Gulick et } \mathrm{al}^{20}}^{20}$ & Soreness & - & + & $?$ & $?$ & - & - & - & $?$ & $?$ & + & - & $2 / 10$ \\
\hline Pope et al ${ }^{21}$ & Injury & + & + & $?$ & + & - & - & + & + & + & + & + & $7 / 10$ \\
\hline Pope et al ${ }^{22}$ & Injury & + & + & $?$ & $?$ & - & - & - & - & ? & + & + & $3 / 10$ \\
\hline
\end{tabular}

*Column numbers correspond to the following criteria on the PEDro scale:

1 -eligibility criteria were specified

2-subjects were randomly allocated to groups (or, in a crossover study, subjects were randomly allocated an order in which treatments were received) 3 -allocation was concealed

4-groups were similar at baseline

5-subjects were blinded

6-therapists who administered the treatment were blinded

7 -assessors were blinded

8 - measures of key outcomes were obtained from more than $85 \%$ of subjects

9-data were analysed by intention to treat

10 - statistical comparisons between groups were conducted

11 - point measures and measures of variability were provided.

†The total score is determined by counting the number of criteria that are satisfied, except that scale item 1 is not used to generate the total score, so total scores are out of 10 .

+ Indicates the criterion was clearly satisfied, - indicates that it was not, ? indicates that it is not clear if the criterion was satisfied. 


\section{What is already known on this topic}

Reviews of the effects of stretching before exercising have drawn conflicting conclusions

The literature on effects of stretching before and after exercising on muscle soreness and risk of injury has not been systematically reviewed

\section{What this study adds}

Stretching before and after exercising does not confer protection from muscle soreness and stretching before exercise does not seem to confer a practically useful reduction in the risk of injury

cising by, on average, less than $2 \mathrm{~mm}$ on a $100 \mathrm{~mm}$ scale. Most athletes will consider effects of this magnitude too small to make stretching to prevent later muscle soreness worth while.

\section{Effects of stretching on risk of injury}

The pooled estimate from two studies was that stretching decreased the risk of injury by $5 \%$. This effect was statistically non-significant. Even if this effect was not simply a sampling error it would not be large enough to be of practical significance. In army recruits, whose risk of injury in the control condition is high (approximately $20 \%$ over the training period of 12 weeks), a $5 \%$ reduction in relative risk implies a reduction in absolute risk of about $1 \%$. Thus, on average, about 100 people stretch for 12 weeks to prevent one injury and (if the hazard reduction was constant) the average subject would need to stretch for 23 years to prevent one injury. ${ }^{21}$ Most athletes are exposed to lower risks of injury so the absolute risk reduction for most athletes is likely to be smaller still. ${ }^{29} 30$

Although these data imply that the muscle stretching protocol used in these studies does not appreciably reduce risk of injury in army recruits undergoing military training, it is not possible to rule out with certainty a clinically worthwhile effect of other stretch protocols on risk of injury in other populations. It would be particularly interesting to determine if more prolonged stretching carried out by recreational athletes over many months or years can produce meaningful reductions in risk of injury.

We thank Rodney Pope for allowing us to use raw data from his studies and for performing the analysis of clustering.

Contributors: RDH and MG designed, analysed, and wrote up the review. MG conducted the search and extracted data with assistance from RDH. Both authors are guarantors for the paper.

Funding: None

Competing interests: None declared.
1 DeVries HA. Prevention of muscular distress after exercise. Res $Q$ 1961;32:177-85.

2 DeVries HA. Electromyographic observations of the effects of static stretching upon muscular distress. Res $Q$ 1961;32:468-79.

3 Gleim GW, McHugh MP. Flexibility and its effects on sports injury and performance. Sports Med 1997;24:289-99.

4 Cross KM, Worrell TW. Effects of a static stretching program on the incidence of lower extremity musculotendinous strains. J Athletic Training 1999;34:11-4.

5 Hartig DE, Henderson JM. Increasing hamstring flexibility decreases lower extremity overuse injuries in military basic trainees. Am J Sport Med 1999;27:173-6.

6 Gleim GW, Stachenfeld NS, Nicholas JA. The influence of flexibility on the economy of walking and jogging. J Orthop Res 1990;8:814-23.

7 Handel M, Horstmann T, Dickhuth HH, Gulch RW. Effects of contract-relax stretching training on muscle performance in athletes. Eur JAppl Physiol 1997;76:400-8

8 Chalmers I, Altman DG, eds. Systematic reviews. London: BMJ Publishing, 1995

9 Dickersin K, Scherer R, Lefebvre C. Identifying relevant studies for systematic reviews. BMJ 1994;309:1286-91.

10 Verhagen AP, de Vet HC, de Bie RA, Kessels AG, Boers M, Bouter LM, et al. The Delphi list: a criteria list for quality assessment of randomized clinical trials for conducting systematic reviews developed by Delphi consensus. J Clin Epidemiol 1998;51:1235-41.

11 Moseley AM, Maher C, Herbert RD, Sherrington C. Reliability of a scale for measuring the methodological quality of clinical trials. Proceedings of the Cochrane colloquium. Rome, Italy: Cochrane Centre, 1999:39.

12 NHS Centre for Reviews and Dissemination. Undertaking systematic reviews of research on effectiveness-CRD guidelines for those carrying out or commissioning reviews. York: University of York, 1996.

13 Laird NM, Mosteller F. Some statistical methods for combining experimental results. Int J Technol Assess Health Care 1990;6:5-30.

14 Wilson GJ, Elliott BC, Wood GA. Stretch shorten cycle performance enhancement through flexibility training. Med Sci Sports Exerc 1992;24:116-23.

15 Buroker KC, Schwane JA. Does postexercise static stretching alleviate delayed muscle soreness? Physician Sportsmed 1989;17:65-83.

16 Johansson PH, Lindstrom L, Sundelin G, Lindstrom B. The effects of preexercise stretching on muscular soreness, tenderness and force los following heavy eccentric exercise. Scand J Med Sci Sports 1999;9:219-25.

17 McGlynn GH, Laughlin NT, Rowe V. Effect of electromyographic feedback and static stretching on artificially induced muscle soreness. $A m$ JPhys Med 1979;58:139-48.

18 High DM, Howley ET, Franks BD. The effects of static stretching and warm-up on prevention of delayed-onset muscle soreness. Res $Q$ 1989;60:357-61.

19 Wessel J, Wan A. Effect of stretching on the intensity of delayed-onset muscle soreness. Clin J Sports Med 1994;4:83-7.

20 Gulick DT, Kimura IF, Sitler M, Paolone A, Kelly JD. Various treatmen techniques on signs and symptoms of delayed onset muscle soreness. J Athletic Training 1996;31:145-52.

21 Pope RP, Herbert RD, Kirwan JD, Graham BJ. A randomized trial of preexercise stretching for prevention of lower-limb injury. Med Sci Sport Ex 2000;32:271-7.

22 Pope RP, Herbert RD, Kirwan JD. Effects of ankle dorsiflexion range and pre-exercise calf muscle stretching on injury risk in army recruits. Australian J Physiother 1998;44:165-77.

23 Donner A, Donald A. Analysis of data arising from a stratified design with the cluster as unit of randomization. Stat Med 1987;6:43-52.

24 Shrier I. Stretching before exercise does not reduce the risk of local muscle injury: a critical review of the clinical and basic science literature. Clin J Sports Med 1999;9:221-7.

25 Smith CA. The warm-up procedure: to stretch or not to stretch. A brie review. J Orthop Sports Phys Ther 1994;19:12-7.

26 Safran MR, Seaber AV, Garrett WE. Warm-up and muscular injury prevention. An update. Sports Med 1989;8:239-49.

27 Thornton A, Lee P. Publication bias in meta-analysis: its causes and consequences. J Clin Epidemiol 2000;53:207-16.

28 Grégoire G, Derderian F, Le Lorier J. Selecting the language of the publications included in a meta-analysis: is there a Tower of Babel bias? J Clin Epidemiol 1995;48:159-63.

29 Glasziou PP, Irwig LM. An evidence based approach to individualising treatment. BMJ 1995;311:1356-9.

30 Herbert RD. Critical appraisal of clinical trials. II: Estimating the magnitude of treatment effects when outcomes are measured on a dichotomous scale. Australian J Physiother 2000;46:309-13.

(Accepted 21 March 2002) 